seem probable that it acts in the same way towards the Leishman-Donovan body whose envelope is also permeable; moisture disorganises this body-a dry syringe is necessary when splenic punctures are made for diagnosis of kala-azar-and we also know by experience how difficult it is to find the Leishman-Donovan bodies in the splenic or liver smears post mortem and in the sections of dead tissues, so sensitive are they to the environment that directly death takes place they disappear-i.e., break up, and cannot be demonstrated.

We can understand these facts if there be free and easy communication through the limiting membranethe envelope of the L.D. body. The permeability of the L.D. body envelope or membrane is further indicated by the kala-azar temperature chart and also by the profound constitutional disturbances caused by the disease-the body inside the envelope manufacturing waste products, toxic to the human organism, which escape through the shell and are possibly replaced by pabulum passing in from without. Practical advantage is taken of the permeability of enclosing membranes of organisms when staining for the microscope, and I wish here to emphasise its clinical importance. Antimony tartrate kills the myracidium lying in the bilharzia ovum; after a few grains have been injected for bilharziasis the ova are very difficult to find in the urine, having apparently been arrested in their progress to the lumen of the bladder. This arrest is not easily explained if the ova are merely foreign bodies embedded in the tissues acting simply as such; if they were, they would behave in the same way before and after injection. Normally they are apparently vital bodies, having automatic action; it seems that only when the motor machinery inside the myracidium is killed by the antimony tartrate does it become a foreign body simply.

To return to the case of kala-azar under discussion. The enlarged spleen and liver did not satisfactorily diminish under A.T. injections alone; $10 \mathrm{gr}$. of quinine were therefore given every morning from 25/5/18 to 11/7/18 (47 days). ${ }^{10}$ Quinine was apparently necessary to this end; $10 \mathrm{gr}$. of quinine daily were given by mouth for 47 days, after which the spleen could not be felt, and the liver was not enlarged to percussion and palpation. Administration of quinine, together with injections of A.T., is thus advisable in kala-azar, when the spleen and liver do not satisfactorily diminish in size.

In bilharzia, kala-azar, and I believe also in trypanosomiasis, the initial effect of injecting antimony tartrate is a marked increase in constitutional disturbance, shown in bilharzia by increase of blood in the urine and aggravation of the local symptoms, in kala-azar by the rise in temperature often to $106^{\circ}$ or $107^{\circ}$, and in sleeping sickness by aggravation of symptoms. The first effect of intravenous injection of antimony tartrate is, therefore, to provoke the disease by liberation of toxins into the circulation. Later, as the blood stream becomes more laden with antimony, the parasites are killed. This point of view is supported "l by the initial increase of eosinophilia in bilharziasis during the course of injections; the differential count of the white blood cells afterwards becomes normal. (The large mononuclear cells also increase when antimony tartrate is injected in bilharzia.)

Summary.

To sum up. Experience seems to show that a few grains of antimony tartrate $(5-8 \mathrm{gr}$.) by intravenous injections may be sufficient to cure leishmaniasis of the skin, ${ }^{12}$ more (20-30 gr.) are necessary, as a rule, to bring about a cure in bilharziasis, and still more $(60 \mathrm{gr}$. , perhaps, and more) are necessary for leishmaniasis or

${ }^{9}$ Althongh L.D. bodies may be found plentifully in spleen and liver smears, they are hard to find in the peripheral blood of a patient, in spite of the fact that the splenic blood-vessels communicate freely with the systemic vessels. Possibly they dis integrate when they find themselves in the peripheral circulation. 10 The boy came from Cinga on the Blue Nile; possibly he had chronic malaria, although no malaria parasites were found in the

${ }^{11} \mathrm{It}$ is also supported by the temperature curve in kala-azar during the course of injections. Follow the chart publisbed.

Provided that the sores are not secondarily infected with a staphylococcal or streptococcal infection; otherwise thes will not heal so soon, although the leishmanic infection will clear up. kala-azar, and possibly still more (probably in repeated courses) for the cure of trypanosomiasis.

Antimony tartrate (pot. or sod.) when given intravenously in appropriate dilution and administered with care may be given in larger total doses than is generally supposed.

The blood, considered as a tissue, is probably capable of withstanding more physical and chemical ill-usage than any other organ; but owing to its structure and distribution it is obviously incapable of resisting micro organic invasion, and is the logical route for direct attack upon micro-organic and other diseases, particularly those of the blood stream itself.

The cure of parasitic diseases, such as bilharzia, kalaazar, trypanosomiasis, filariasis, dracunculus medi nensis, by a drug given intravenously (the drug itself if it acts directly, or a derivative if it acts indirectly) depends on: (1) the permeability of the enclosing membrane (or skin) of the parasite; (2) the penetrating power of the drug which in turn depends on its physical condition or chemical structure; (3) the toxicity of the drug to the parasite.

\section{THE OUT-PATIENT TREATMENT OF}

BILHARZIASIS,

WITH AN ANALYSIS OF 1000 CASES.

BY H. B. DAY, M.C., M.D. LoND., F.R.C.P. LoND., PHYSICIAN, KASR-EL-AINI HOSPITAL, CAIRO.

THE war-time discoveries of the Bilharzia Mission under R. T. Leiper, and of J. B. Christopherson, N. H. Fairley, and others concerning the early signs of infection, the life-history of the parasite, and a specific remedy against it, have rendered possible a campaign against the ravages of the disease in Egypt. Since bilharziasis affects no less than 80 per cent. of the asgricultural population in this country, it is evident that preventive measures must depend largely for their success on the awakening of an intelligent knowledge of the disease among the peasantry. It is hoped that by systematic instruction in the schools and by exhibition of posters and kinematograph films public interest will be aroused to the possibility of avoiding worm diseases and other infections and to the necessity of early treatment for curable maladies.

As a preliminary to work on a wider scale, it appeared desirable to test the methods of treatment advocated for bilharziasis, with a view of learning their possibilities and limitations. Experience soon showed that in-patient treatment was impracticable for most patients. The pressure on hospital beds prevented the admission of any but severe and complicated cases, and the average Egyptian would not stay in hospital unless seriously incapacitated. To overcome this difficulty permission was obtained from the Department of Public Health to erect a tent annexe at Kasr-el-Aini Hospital for the out-patient treatment of bilharziasis and ankylostomiasis. The particular subjects for investigation were twofold: (1) to test the practical value of out-patient treatment of bilharziasis as regards the attendance of patients and the efficacy of routine treatment; (2) to find the best methods of specific treatment and the minimum dosage and attendance necessary for the average case.

The annexe was opened in December, 1919, and put under the immediate charge of successive clinical assistants. To these doctors I am deeply indebted for all the clinical work and for invaluable assistance in the examination of the microscopic specimens necessary for scientific control. The annexe consists of marquee tents, pitched inside the hospital square, and arranged in two sections, male and female. They are provided with stretchers (on trestles) and blankets, and latrine accommodation is attached. A central marquee serves for examination and treatment. Each patient receives a numbered attendance card, which corresponds to a page in the registers in which all particulars are entered. At each visit a specimen of urine (or stool if indicated) is obtained and its appearance noted, 
while at appropriate intervals the specimen is kept for microscopical study.

\section{Analysis of Cases Treated.}

Number of patients. - The annexe has been well patronised from the start, being supplied from the numbers of bilbarzial patients presenting themselves in the out-patient departments. From 100 to 200 new patients are seen every month, as is shown in the following table:-

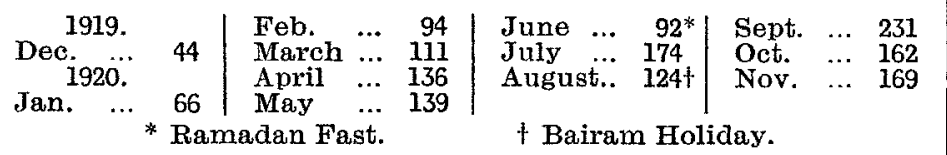

These numbers are exclusive of 115 anks lostoma patients also treated at the annexe during the last nine months.

For analysis the first 1000 cases have been taken :Sex.-There were 897 male and 103 female cases.

Age.-Patients were of all ages, ranging from $2 \frac{1}{2}$ years to over 60 . 118 were children not exceeding 10 years of age.

Types of infection.-The great majority of patients were suffering from urinary disease, as is shown below:-

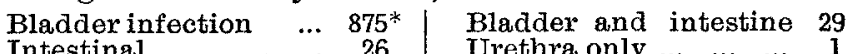
$\begin{array}{lllllllllll}\text { Intestinal } & \ldots & \ldots & \ldots & 26 & & \text { Urethra only } & \ldots & \ldots \\ & & \text { Total } & \ldots & \ldots & \ldots & \ldots & \ldots & \ldots & \ldots & 931\end{array}$

* Of these 111 were complicated by septic cystitis, 4 by fistula, and 2 by filariasis.

In addition, one case of chyluria (filarial) was also treated.

Selection of cases.-Only patients with active infection are suitable for specific treatment. The passage of blood at the end of micturition, or of bloody mucus with defæcation, is the usual clinical sign, and the diagnosis must be made by finding living bilharzia ova on microscopical examination. So long as living ova are present, the existence of secondary bacterial infections of moderate degree is no bar to successful treatment. But patients with advanced disease often present the signs of septic cystitis, and frequently pyonephrosis, while no ova, or only a few dead ova, are found on thorough examination. In such cases antimony treatment is useless, and therefore prejudicial to the reputation of the drug.

Contra-indications. -The chief of these, other than that above mentioned, is severe cardiac, arterial, or renal disease. Even a fairly advanced degree of hepatic cirrhosis need not be a deterrent, but doubtful cases are unsuited to out-patient treatment, and, indeed, cannot attend properly. We have also avoided giving antimony injections during pregnancy. On these grounds 68 out of the 1000 cases were rejected as unsuitable. Two bilharzial patients were admitted to the wards on account of their bad general condition, and two of the women were advised to wait until the termination of their pregnancy. Twenty-eight patients were rejected on account of advanced bladder and kidney disease, with no evidence of active bilharzial infection. The remaining 36 patients were found to be suffering from other diseases and not from bilharziasis.

Subsequent attendance.-One-third of the patients ceased attending after one to three visits, being unwilling or unable to continue treatment. Several returned later and took a full course. These return cases are omitted in the following table, which shows the total amount given in the ordinary way :-

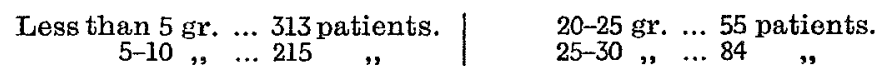

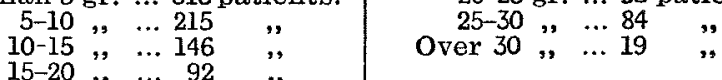

Four patients refused injections; four others were treated by injections of colloidal antimony only

On the whole these figures are satisfactory. Many of the patients had little disease, and to that they were well inured, so that the duration and inconvenience of the necessary treatment deterred them from continuing their course. A large number of patients ceased their visits as soon as their symptoms were relieved, as usually occurs within a week or two of commencing treatment. On the other hand, most patients with septic cystitis as a complication were diligent in attendance, though little benefit could be procured. The remainder, a considerable proportion, persevered and took as many injections as were deemed necessary.

Method of injection.-For good and rapid work a full light, a handy assistant, and a sharp needle on a glass syringe are needed. The requisite quantity of a 6 per cent. solution of tartar emetic ( $1 \mathrm{gr}$. in $1 \mathrm{c.cm}$.) is drawn up into the sterile syringe followed by some c.cm. of sterile saline. The patient lies on an operating couch with his arm extended and supported on a small three-legged table, with a $\Delta$-shaped top, whose base abuts against the couch. The skin in front of the patient's elbow is swabbed with alcoholic picric solution by the attendant, who then grasps the arm above, while the patient clenches his fist to distend the veins. As soon as the needle has been shown to lie truly in the lumen of the vein by the free entry of blood, the attendant relaxes his hold and the injection is made. The patient then holds up his arm to arrest any bleeding and goes out to rest in the adjoining tent. The injections are given in the middle of the juorning when the stomach is fairly empty and the drug has least untoward effect. Special care is necessary in making the injection, since tartar emetic is a most irritating compound to the tissues and causes severe inflammation if introduced outside the vein.

Course of treatment.-To adults was given an initial dose of $1 \mathrm{gr} ., 1 \frac{1}{2} \mathrm{gr}$. the next time, and $2 \mathrm{gr}$. on each subsequent occasion. Not many out-patients could take a larger dose without suffering from persistent giddiness and often vomiting. Young women and youths generally took $1 \frac{1}{2} \mathrm{gr}$. as a full dose, and it was found that many children could tolerate this amount. The injections were given as a rule on alternate days. Many patients were somewhat irregular in attendance and received only two, or even one, injection per week. The duration of treatment was controlled by observing the effect on the ova.

Examination of ova.-The urine is allowed to stand in a specimen glass; its appearance and the nature of any deposit is noted. The lowest layer is then transferred to a centrifuge tube and washed by centrifuging and shaking with successive quantities of water. Since the ova are relatively heavy they are brought down by a few turns of the handle, while most of the blood and pus corpuscles are left suspended, and can be poured off with the supernatant fluid. The sediment is finally transferred by a pipette to a shallow glass cell affixed to a microscope slide. By filling the cell above its brim and dropping on a cover-glass air bubbles are avoided and evaporation retarded, if it is desired to postpone examination until living miracidia have hatched out. Half an hour in an incubator at $37^{\circ} \mathrm{C}$. will hasten matters in cold weather.

Under regular treatment by tartar emetic the phenomena outlined by Christopherson ${ }^{\prime}$ occur as follows :-

(a) By the end of the first week there is a noticeable diminution in the amount of blood and number of ova passed in the urine. In mild cases blood is no longer visible to the naked eye.

(b) About the ninth day the ova begin to hatch out more slowly; the miracidia are less active and die quickly.

(c) By the end of the second week a considerable proportion of the ova fail to hatch. The shells of these ova are distended as usual by imbibition of water, but the enclosed miracidia show little or no movement. Small immature ova are frequently seen whose contents appear brown and granular instead of a translucent clearness.

(d) During the third week the toxic effect of the drug becomes very evident. The few miracidia that hatch out are usually globular in shape, move very sluggishly, and soon die in distorted shapes. Most of the ova no longer swell in water, while the delicate and refractile structure of the contained miracidium becomes obscure and granular. Death of the embryo is followed by a deepening opacity; the contents of the shell become brownish, and altimately black, by trans mitted light. This change occurs first in the cells and granules around the embryo, and later in the degenerated miracidium itself.

(e) By the end of the third week or during the fourth all the ova are dead, most being black. These black ova are often passed in masses held together by mucus. As many as 200 to 300 may sometimes be found in a specimen of urine even a month or longer after the conclusion of treatment, but in most cases the ova become scanty and difficult to find.

Similar phenomena are found in the case of intestinal disease due to the Bilharzia mansoni, with its lateralspine ova and slightly larger miracidia. It should be borne in mind that ova left in contact with frees or 
alkaline urine perish quickly, and so often fail to hatch $/$ emetic. ${ }^{1}$ This fact, coupled with the special influence on the subsequent addition of water. Also, that rough handling will rupture the shells of ova whether dead or alive, so that the finding of an empty shell is no proof of a living embryo. A preliminary search of the specimen before the ova have time to hatch naturally will obviate this error.

Immediate results. - The effects of injections on the ova are shown on the charts in diagram form. The curve shows the percentage of dead ova present, not the total numbers, and the figures beneath record the dose in grains of each injection. Chart 1 illustrates a typical case. When injections are given at long intervals the effect is delayed, as is well seen in of an early concentration of the drug on the ova, made it appear possible to obtain the curative effect of the remedy by quite a short course of treatment, thus taking advantage of the cumulative action of antimony. On trial this method was found to succeed, four or five injections (a total of 8 to $9 \mathrm{gr}$.) being sufficient to kill the ova if given in the first ten days or so, and their effect looked for at the expiry of the usual intervalabout a fortnight later (see Chart 5).

Late results. - Further experience proved that this short course was unsatisfactory, since re-examination two or three months later showed the recurrence of living ova in patients who had not been exposed to

In the following Charts the Curve shows the Percentage of Dead Ova present on Examination of the Urine Day of treatment.

(reading from the left). The figures beneath record the Dose in Grains of each Injection.

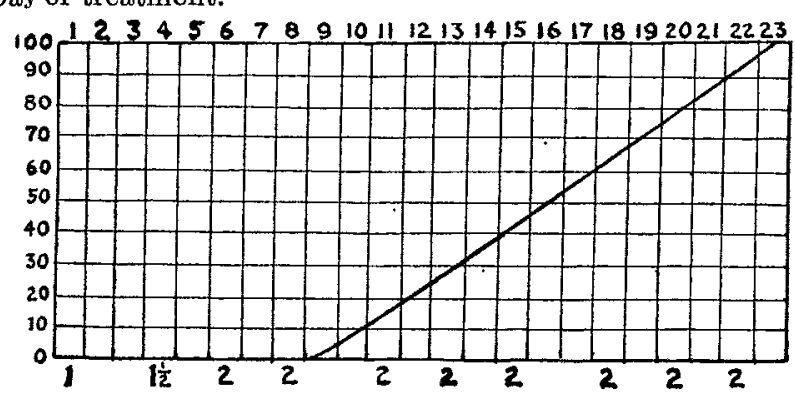

Chart 1.-Male, age 22, weight 10 st. Bilharzia of bladder 15 years, of intestine 1 year. Treated with tartar emetic (intravenous injections).

Day of treatment.

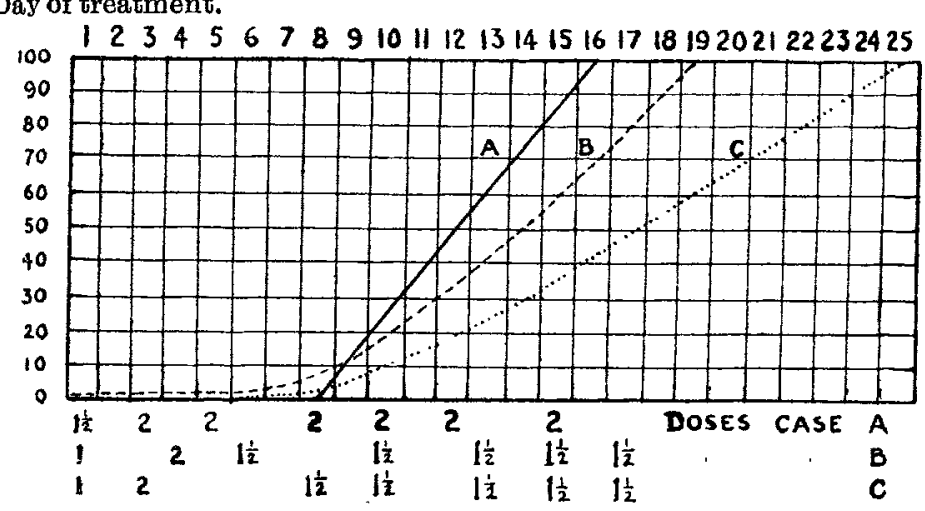

Chars 3.-To show the comparative progress in three patients with bilharzial disease of bladder. Ages 19 to 26, weight of each $9 \mathrm{st.} 9 \mathrm{lb}$. Treated with tartar emetic (intravenous injections). In spite of the small total dose permanent cures were obtained.

Day of treatment.

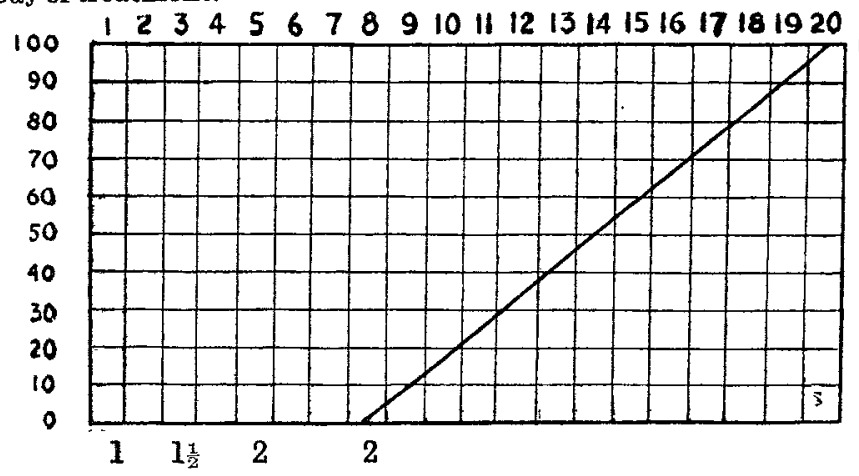

Chart 5.-Male, age 21, weight 9 st. 12 lb. Bilharzia of bladder 10 years. Treated with tartar emetic (intravenous injections).

Chart 2. To secure a quick result it is important to raise the concentration of antimony in the circulation by giving frequent injections in the first week. Chart 3 records the results in three patients of identical weight, who received different amounts of the drug during this period. In each case eight days elapsed before any definite effect was observed, but the subsequent progress varied in rate of cure. Occasionally one can observe the effect of one or two doses only, which is characteristically transient (see Chart 4). Now chemical analysis of the urine of patients has shown that the excretion of antimony is maintained for some two or three weeks at a high level after the termination of a full course of tartar

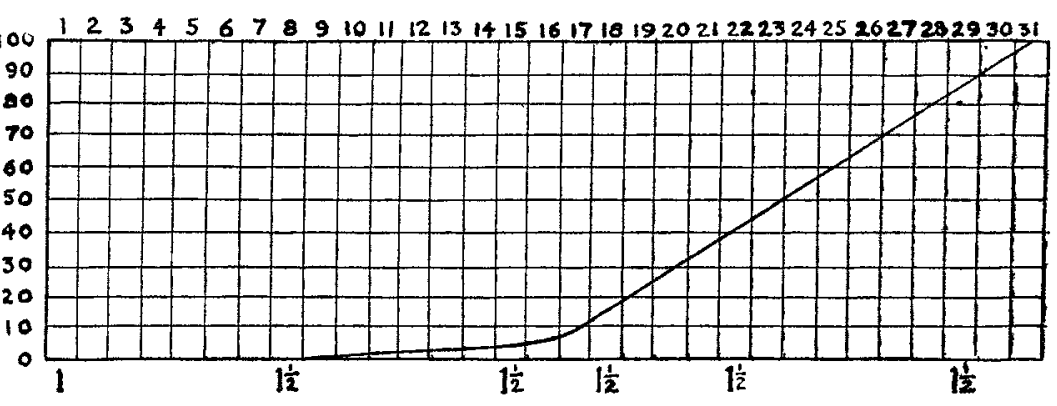

Treated with tartar emetic (intravenous injections)

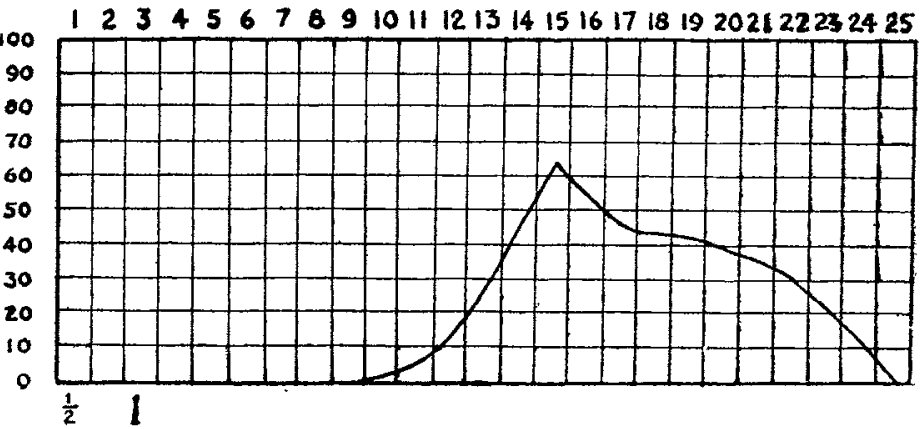

Chart 4.-Boy, age 7, weight, 2 st. $12 \mathrm{lb}$. Bilharzia of bladder 15 months. Treated with tartar emetic (two intravenous injections)

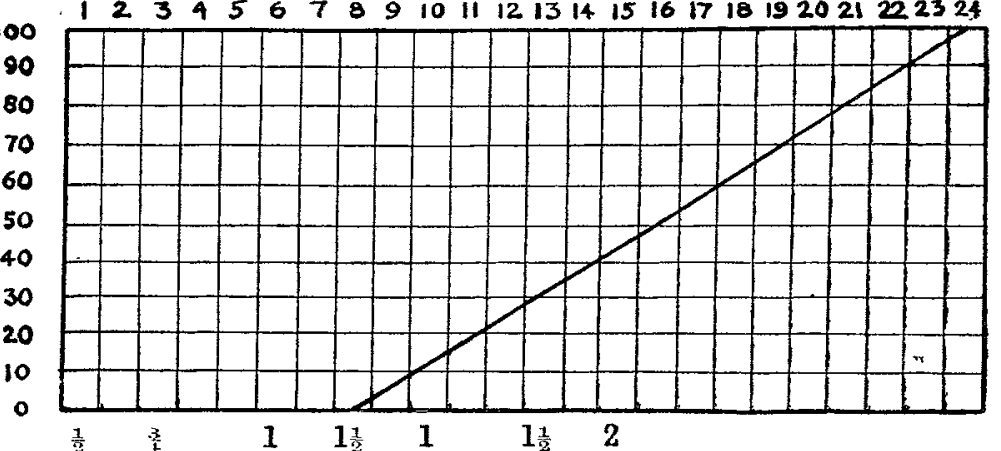

ChaRT 6.-Girl, age 8, weight 3 st. $13 \mathrm{lb}$. Bilharzia of bladder 5 months Treated with emetine (intramuscular injections).

reinfection. Few adult patients appear to have been permanently cured by a smaller dose than $13 \mathrm{gr}$. , although the number of ova may be very greatly reduced when seen some months afterwards. The occasional finding of a living ovum after a full course of treatment may be explained by the survival of ova which have possibly been protected against the influence of the drug by lying enclosed within a giant cell, as is not infrequent. But the reappearance of living ova in increasing numbers can only mean the presence of living worms. Hence we may conclude that the primary effect of antimony in bilharziasis is the destruction of the ciliated embryos within their shells, and that the parent worms require a larger lethal dose. This result is more in keeping 
with the experience of Sir Leonard Rogers ${ }^{2}$ (which we have conflrmed), that in the treatment of filariasis a large amount, of antimony is necessary to reduce permanently the numbers of microflariæ in the circulation. The bilharzia worm can be found alive in the portal vein for many hours after the death of the patient from toxic diseases, and on experiment is found to mesist quite considerable concentrations of antiseptics. Leiper and Christopherson inform me that they believe the bilharzial ovum is endowed with the power of digesting its way through the tissues. Hence the reduction of the hæmaturia and number of ova passed in the first week of treatment may be explained by a functional disability of the miracidia preceding their death, and not necessarily by a similar effect on the egg-laying worms.

Optimum dose.-For adults we may place the minimum effective dose at about $13 \mathrm{gr}$., but a larger amount is generally necessary. For considerable variations are observed in the amount of antimony needed to cause permanent disappearance of living ova. Thus two brothers, aged respectively 13 and 17 , attended the annexe together and received the same number of injections. The elder received a total of $28 \frac{1}{2}$ gr., and six weeks later his urine was found to contain a very few dead ova. The younger received $19 \frac{1}{2} \mathrm{gr}$., but had a more severe infection, and six weeks after the course was terminated a specimen of urine contained seven living and two dead ova. A specimen before treatment contained some hundreds of living ova, so that treatment could not be considered a failure. Even a total of 25 to $30 \mathrm{gr}$. has not uniformly succeeded in permanently banishing living ova. It is probable that the effect of treatment depends to some extent on the condition of the worms and the ova present. An adult with disease contracted in childhood who has not been exposed to reinfection for years may need a smaller dose for his cure than would another patient recently infected with vigorous parasites. This theory may explain why $12 \mathrm{gr}$. can cure one case, while double that amount may be needed for another patient of similar size.

As the result of our experience with out-patients the following course is recommended for an adult :-

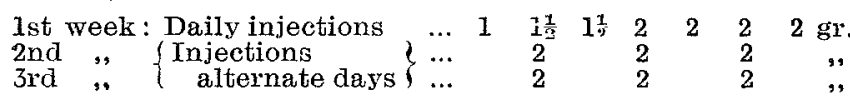

The amount of each dose is regulated by the size, condition, and tolerance of the patient. Under this system the usual course for an adult totals 24 gr., and the omission of one or two doses owing to irregular attendance will hardly affect the result.

The urine is examined at the end of the course and again after a week, when a further course can be given in the unlikely event of ova surviving. The patient should report about three months later.

Complications. - Specific treatment is of great value before operations are undertaken for the closure of urinary fistulio or excision of polypi, \&c., complicating bilharziasis. Thus F. O. Lasbrey and R. B. Coleman ${ }^{5}$ at the C.M.S. Hospital, and the members of our own surgical staff, find that post-operative healing is vastly accelerated in such cases once the causative infection has been removed. About 10 per cent. of our cases of urinary bilharziasis are complicated by a secondary septic cystitis. If the amount of pus present is quite moderate the cystitis generally disappears after the ova are killed, but a severe cystitis is hardly affected, though hæmorrhage usually ceases.

Treatment by other arugs.- The effect of other remedies has been tested and new preparations are on trial. Colloidal antimony is effective, but the ampoules only contain about $2 \mathrm{c.cm}$., a dose which is only successful in quite small children, adults requiring 5 to $10 \mathrm{c} . \mathrm{cm}$. each injection. This preparation has the great advantage that it can be given by intramuscular injection. Emetine in large doses has been found effective by Diamantis ${ }^{3}$ and $A$. Erian, ${ }^{t}$ and we have confirmed their results. The remedy is best given intravenously, as a large dose is irritating to the tissues. The dose is from $\frac{1}{2}$ to $3 \frac{1}{2} \mathrm{gr}$. for each injection, according to the weight and tolerance of the patient, and the course is similar to that for tartar emetic. Chart 6 illustrates the effect on the ova produced by a course of emetine. The high cost of emetine militates against its routine use for out-patients. But it is a most useful alternative to use under certain conditions, viz.: $(a)$ for young children or others whose veins are too small or inconspicuous for intravenous injections; (b) for patients who exhibit an intolerance for tartar emetic or where an error in technique has resulted in abscess (c) for cases of bilharzial dysentery complicated by amœbiasis.

\section{Anliylostoma Patients.}

Cases without severe anæmia have been treated as out-patients in the annexe. The patient is instructed to come fasting in the morning but to bring some food with him to be taken after treatment. He is accom. modated on a stretcher and is given 10 drops of oleum chenopodii on sugar at intervals of one and a half hours until three doses have been taken. One hour later he has a dose of castor oil. Before he leaves he has his food and is given a bottle of iron and arsenic mixture to take home. The treatment is repeated in three days and the stools re-examined after a fortnight.

For the detection of the ankylostoma ova in the fæces the flotation method has proved most convenient and satisfactory. A small portion of fæces is emulsified in a little water and poured through a coarse strainer into a small flask of conical shape, narrowing to the neck. (A small bottle with sloping shoulders and a wide mouth does equally well.) The flask is then filled to the brim with a saturated solution of common salt in water and left to stand for a few minutes. Portions of the surface film are then taken up by means of a wire loop dipped under the surface and transferred to a slide for microscopical examination. The ova are found concentrated in this surface film, and can be identified with the greatest ease.

Work in the Provinces.

The success of the special annexe at Kasr-el-Aini led the Department of Public Health to open similar establishments in connexion with three provincial hospitals
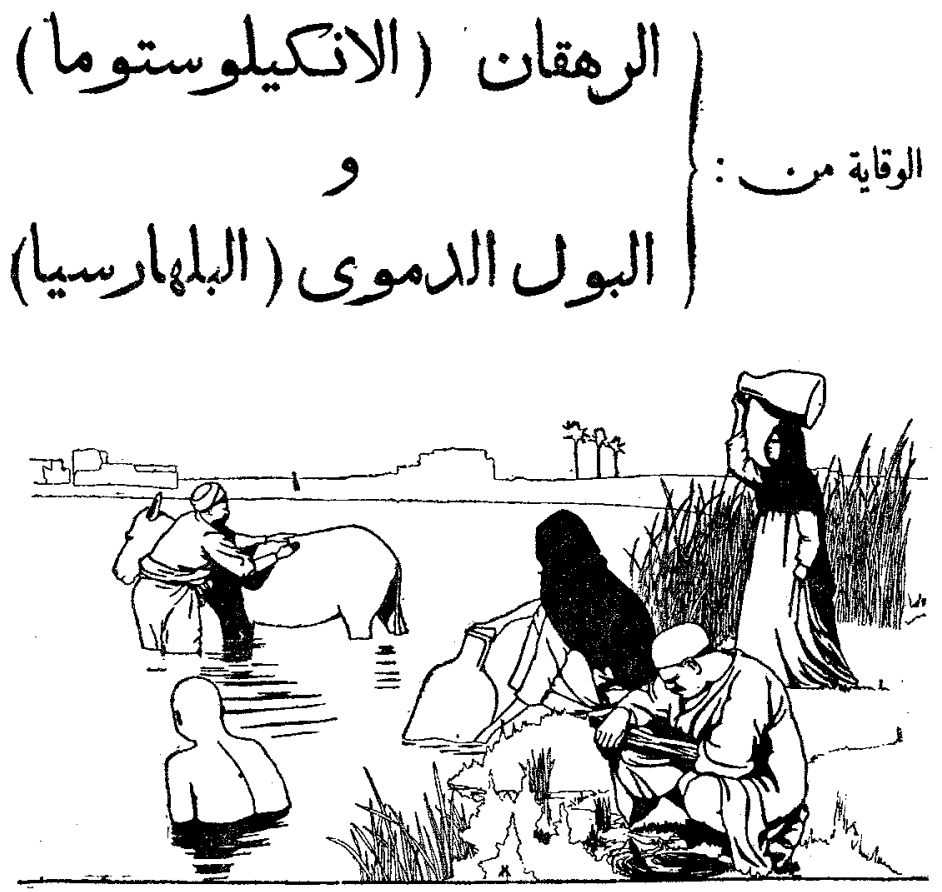

An Esyptian poster heading designed to inculcate the danger of water-born poster heading designed to inculcate the picture signify, reading from right to left:-

$$
\text { The prevention of }\left\{\begin{array}{l}
\text { Anæmia (Ankylostoma) } \\
\text { and } \\
\text { Hæmaturia (Bilharzia). }
\end{array}\right.
$$

in the Delta last summer. These annexes have proved very popular, and their usefulness has been enhanced by the local exhibition of posters, by public lectures, and by the distribution of leaflets. I am indebted to Colonel Garner, Under Secretary of State, Department of Public Health, for permission to reproduce the illustrated heading of one poster, which draws attention to the danger of infecting water. 
Conchusions.

1. The out-patient treatmont of bilharziasis on a large scale is practicable and successful. 2. Due selection of cases and great care in giving the injec tions is necessary. 3. The primary effect of antimony is on the ova. 4. A full course of tartar emetic or alternative drug is required to secure a pormanent cure in most patients. 5. Colloidal antimony and emetine are useful substitutes for tartar emetic when occasion demands. 6. Curative treatment must be combined with the widest measure of public instruction if the incidence of the disease is to be lessened.

References.-1. J. B. Christiophexson and J. R. Newlove: Jour. Trop. Med. and Hygiene, July 15th, 1919. 2. Sir L. Rogers, Brit Med. Jour., 1920, i., p. 596. 3. Diamantis: Journal d'Urologie T. vii., No. 1. 4. A. Erian : Practitioner, November, 1919, p. 391 5. Lasirrey and Coleman: Brit. Med. Jour. (in print)

\section{MOSQUITO-NETS : THEIR USE IN THE PAST.}

By SIR PATRICK HEHIR, K.C.I.E., C.B., C.M.G., M.D., MAJOR-GENERAL, I.M.S. (RFTMRED)

SOME months ago a very useful book on tropical medicine was reviewed in THE LANCET. ${ }^{1}$ In tracing the history of malaria in that work it is stated, inter alia, that mosquito-nets were first used in India in 1881. I would ask the author's permission to allow me to correct this statement. The mosquito-net is much more venerable in India. We have it on record by Surgeon-Major (afterwards Sir James) Annesley, I.M.S. in his "Diseases of India," that mosquito-nets were used as a protection against mosquitoes by Europeans as early as 1828, when his book was published, and possibly they were used at an earlier date. They were then employed, Annesley tells us, to prevent the physical discomfort caused by the bites of mosquitoes, to exclude the "miasmata" that were supposed to give rise to malaria, and to " prevent chills from the night dew." Where the author of the first book referred to above got his date from I do not know; the practical application of Sir Ronald Ross's discovery of the direct relation of mosquitoes to malaria did not form part of routine life in India until the beginning of the present century.

Long before the discovery of malaria parasites by Laveran in 1881 nets were in use in several tropical and subtropical countries. We have it on record as a historical fact that almost a century ago some of our generals and sportsmen in India attributed their freedom from disease to the using of mosquito-nets. I can personally remember mosquito-nets being in use at Poona, Mhow, and Nasirabad when my father's regiment, "The King's," went out to India in 1868; their use was not general at that time, and they were not issued to British troops as they are now.

The native of India has always used his chadar (sheet) or other covering when asleep to protect himself from the attacks of mosquitoes. Even in the hottest weather we find him covering his head and exposed parts of his body with such a garment. I dimly recollect being told or reading somewhere that the Singhalese several centuries ago used some form of a net or covering to protect themselves from mosquitoes. I regret I cannot recall the reference.

Probable Early Antimalarial Measures.

It is possible that if we could ferret out the whole history of the mosquito-net we might find that through the ages the inhabitants of countries infested by mosquitoes have used some sort of protection against their attacks, either in the form of nets or covering, or as applications to the surface. The habit of anointing with scented oils practised by the Babylonians and other ancient Semitic nations may not have been with out its purpose in repelling the attentions of insect life. The Tigris and Euphrates valleys must have been a paradise for insect life from time immemorial. One can

Essentials of Tropical Medicine, by Dr. Walter E. Masters, ThY LANCET, 1920, ii., 406. never forget the appalling postilence of insects that invaded the 6th (Poona) Division during the flrst week of June, 1915, at Frra's Tomb on the Tigris, a place between Basra and Amara. We have the authority of history indicating that some form of mosquito-net was in use thousands of years ago by Egyptians, Greeks. and Romans.

Herodotus and Mosquito-Nets.

A few months ago I was reading Cary's English version of Herodotus and came across an interesting paragraph in this connexion (II., p. 94). Writing of the Egyptians who dwelt on the banks of rivers, lakes, and marshes, Herodotus says :-

They have the following contrivance to protect themselves from musquitoes $(\mathrm{sic})$, which abound very much. The towers are of great service to those who inhabit the upper parts of the marshes; for the musquitoes are prevented by the winds from flying high; but those wholive round the marshes have contrived another expedient instead of the towers, Every man has a net with which in the day he takes fish, and at night uses in the following manner: in whatever bed he sleeps, he throws the net around it, and then getting in, sleeps nnder it; if he should wrap himself up in his clothes or in linen the musquitoes would bite through them, but they nover attempt to bite through the net."

One imagines that the Egyptian fisherman had either great faith in the protection afforded by his net, or he had more confldence in the guilelessness of the genera of mosquitoes inhabiting his neighbourhood than we now entertain as regards mosquitoes of tropical and subtropical countries.

\section{The Roman Conopeum.}

History likewise tells us that the conopeum, or mosquito-net, was used by the Romans. In an admirable résumé of this subject Sir Ronald Ross ${ }^{2}$ quotes Varro, Horace, Propertius, Juvenal, and Paulus Silentiarius as referring to the mosquito-net, and tells us that Horace says: "And among the military standards, oh shame! the sun sees a mosquito curtain," and that Propertius calls these nets foeda (foul or disgraceful); it may be supposed he meant that it was unmanly for the hardy Roman soldier to indulge in the use of such protection against gnats. Personally, I feel that the man who devises a practicable and portable means of protecting troops who are fighting in endemic malarial areas from the attacks of mosquitoes will deserve the highest commendation.

The Possibility of Complete Protection.

The well-known experiment of Drs. G. C. Low, L. W. Sambon, and D. Rees, carried out in the Roman Campagna in 1900 , proved beyond all equivocation that if the body is protected from the attacks of anopheles one may live in even the worst endemic malarial areas without becoming infected. If I remember rightly, Professor J. W. W. Stephens and Lieutenant-Colonel $S$. $R$ Christophers, I.M.S., found the same to be the case in their malaria work in the West Coast a short time afterwards.

In quite recent times one has often been asked seriously by civil servants, military officers, and other educated people in India whether mosquitoes really carried malaria. If some of the better classes entertain doubts of this kind, it is scarcely to be expected that the poorer, uneducated classes in India, including the village ryot, knows what a danger to his health the mosquito is. Yet we require the coöperation of all classes in the reduction of malaria. This points to the necessity of educating the people of India, especially the agricultural population, in the first principles of prevention, and to the fact that for many years to come we should patiently and persistently diffuse this knowledge by propaganda, placards, leaflets, lectures, magiclantern, microscopical, and kinema demonstrations and other means. I gave lectures of this kind for years to various garrisons and other audiences in India." They were usually associated with magic-lantern slide demonstrations of the different forms of adult anopheline and culicine mosquitoes, their larvæ and eggs, malarial parasites in the stomach walls of anophelines, in the blood, and of patients suffering from malarial enlargement of the spleen and malarial cachexia, and taking 